\title{
Establishing the concept of aza-[3 + 3] annulations using enones as a key expansion of this unified strategy in alkaloid synthesis
}

\author{
Aleksey I. Gerasyuto, Zhi-Xiong Ma, Grant S. Buchanan
} and Richard P. Hsung *

\section{Full Research Paper}

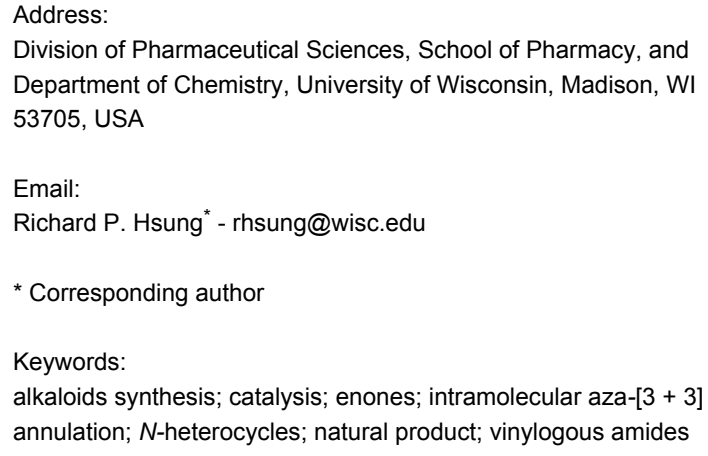

Division of Pharmaceutical Sciences, School of Pharmacy, and Department of Chemistry, University of Wisconsin, Madison, WI 53705, USA

Email:

Richard P. Hsung* - rhsung@wisc.edu

* Corresponding author

Keywords:

alkaloids synthesis; catalysis; enones; intramolecular aza-[3 + 3]

annulation; $N$-heterocycles; natural product; vinylogous amides

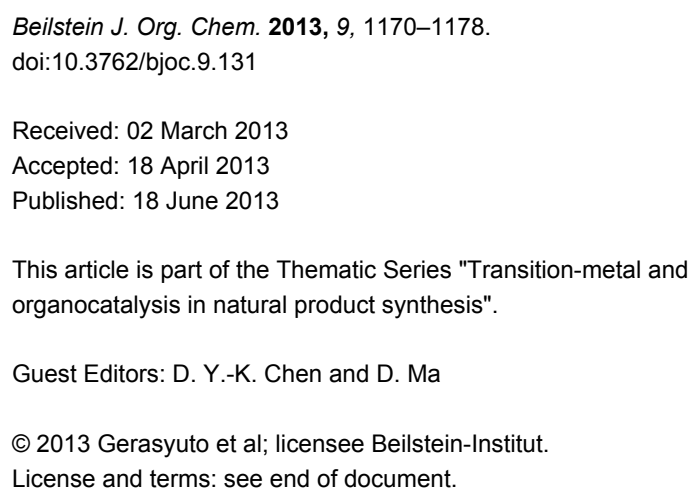

\begin{abstract}
A successful enone version of an intramolecular aza-[3+3] annulation reaction is described here. Use of piperidinium trifluoroacetate salt as the catalyst and toluene as the solvent appears to be critical for a successful annulation. We also demonstrated for the first time that microwave irradiation can accelerate aza-[3 +3$]$ annulation reactions. An attempt to expand the scope of the enone aza- $[3+3]$ annulation was made in the form of propyleine synthesis as a proof of concept. While synthesis of the enone annulation precursor was successfully accomplished, the annulation proved to be challenging and was only modestly successful.
\end{abstract}

\section{Introduction}

Throughout the past decade, we have been developing an aza$[3+3]$ annulation reaction as a general and unified strategy in alkaloid synthesis [1-32]. Our aza-[3+3] annulation, which has been classified as Type-II [1], with Type-I aza-[3 + 3] annulation being reserved for Robinson's double Mannich-type process [33], utilizes readily accessible and easily handled vinylogous amides and vinyl iminium salts. It provides a significant complementary, if not superior, approach to aza-[4+2] cycloadditions in constructing piperidines, because the azadienes and imines required are not always the most accessible and/or easily handled substrates given the problems of isomerization and hydrolysis (Figure 1) [34-37].

The prevalence of six-membered nitrogen heterocyclic motifs in alkaloids renders the development of this aza-[3+3] annulation into a powerful strategy a unique opportunity in the field of 

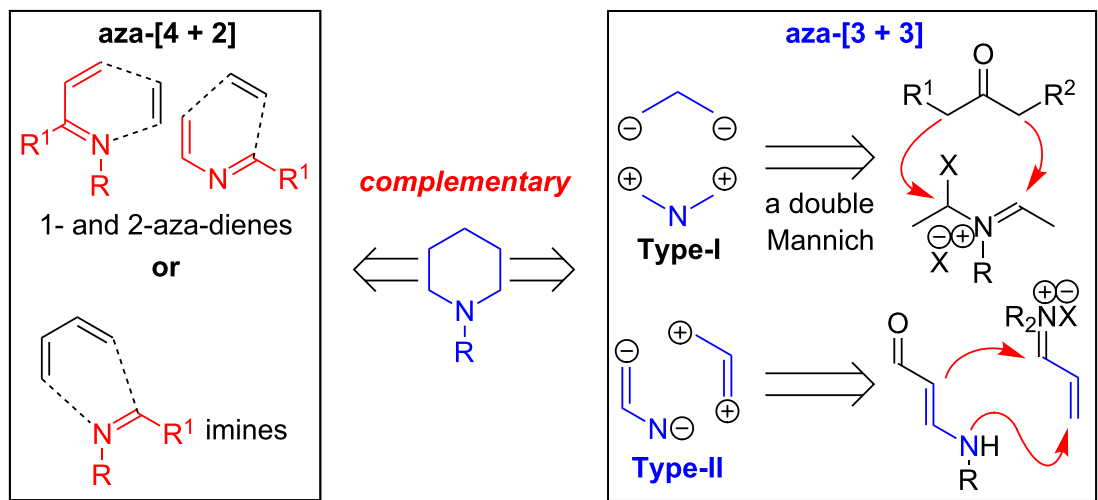

Figure 1: An aza-[3+3] annulation

alkaloid synthesis [1-4,8-15]. The intramolecular variant of this annulation has proven to be particularly valuable for total synthesis [16,26-32]. Specifically, the intramolecular aza- $[3+3]$ annulation of vinylogous amides tethered to a vinyl iminium motif 1a proceeds through a tandem sequence of $\mathrm{N}-1,4$-addition and $\mathrm{C}-1,2$-addition/ $\beta$-elimination $[16,17]$, effectively leading to a variety of nitrogen heterocyclic motifs, such as 3, which are prevalent among alkaloids (Scheme 1) [16,26-32]. However, there was a significant deficiency in this annulation: the inability to employ vinylogous amides tethered to $\alpha, \beta$-unsaturated ketones, or enones $\mathbf{1 b}(\mathrm{R} \neq \mathrm{H})$ (Scheme 1).

Conceptually, employing enals or enones in an aza-[3 +3$]$ annulation appears to constitute very little difference, with the major difference lying in the $\mathrm{R}$ group in their respective products 3 and $\mathbf{4}$. While seemingly an insignificant perturbation, the ability to employ enones in aza-[3 +3$]$ annulations can generate a vast array of opportunities, including the case where $\mathrm{R}$ is as small and simple as a Me group, which would already represent a facile entry to aza-phenylene alkaloids [30,31,38-45], such as propyleine [46-48], as well as lycopodium alkaloids that are rich in bioactivities [49-51] (Figure 2). In addition, the importance of these ventures into an aza-[3+3] annulation with enones can also be further demonstrated through syntheses of tetrahydroisoquinolines and indole alkaloids [52-55] in which the $\mathrm{R}$ group can constitute a larger functionality of the alkaloids, such as that seen in geissoschizine [52-57], and ipecac alkaloids such as protoemetine [48,52-55,58-61], emetine [5255,58-63], and tubulosine [64]. With the appropriate choice of an $\mathrm{R}$ group in the synthetic design, a highly convergent and expedient strategy can come forth for constructing these alkaloids. We report herein our success in achieving intramolecular aza- $[3+3]$ annulations of an enone.

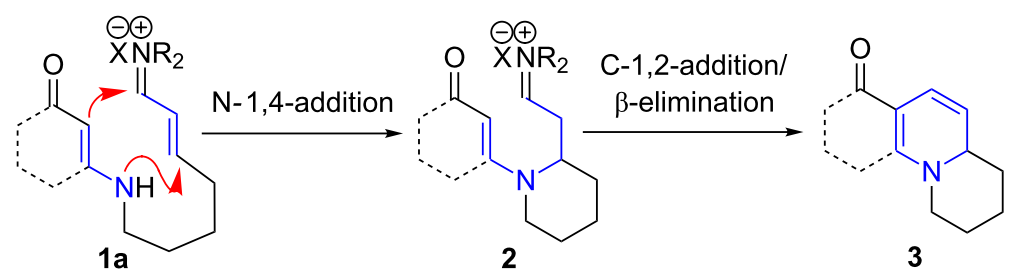

a simple concept: aza-annulation of enones<smiles>CC(C)C1=CC2CCCC2N2CCCCC12</smiles>

3

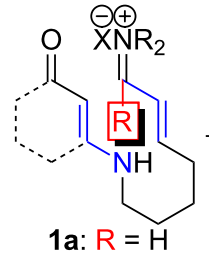

$1 b: R \neq H$<smiles>[R7]C1=C[C@H]2CCCCN2[C@H]2CCCC(=O)C12</smiles>

4: not found 


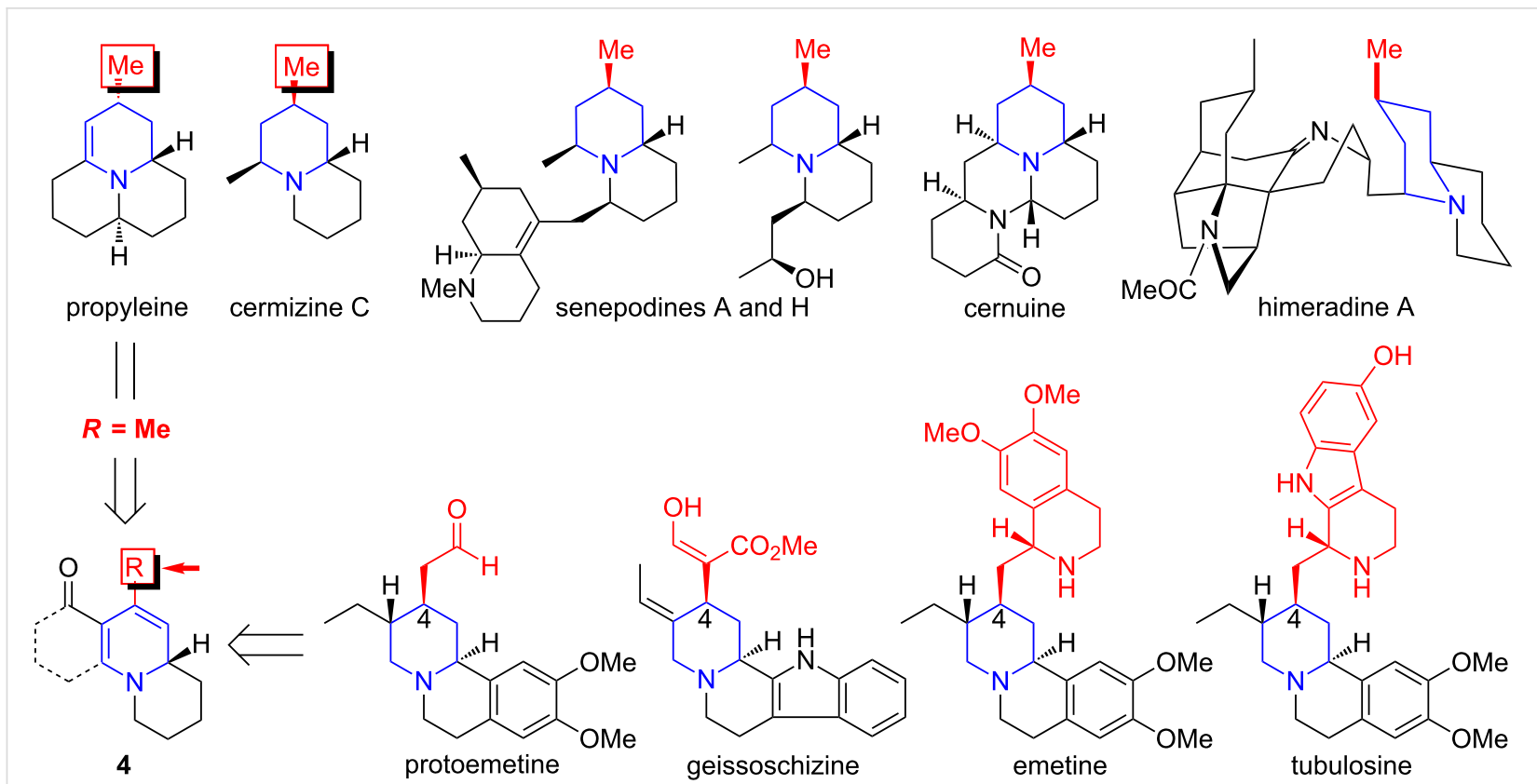

Figure 2: Possible natural-product targets.

\section{Results and Discussion}

To examine the feasibility of an enone intramolecular aza$[3+3]$ annulation, a seven-step synthesis of the annulation substrate 10 commencing from 3-butyn-2-ol (5) was carried out (Scheme 2). Protection of secondary propargyl alcohol $\mathbf{5}$ as the THP-ether followed by alkylation of a lithium acetylide onto 1,4-dibromobutane afforded bromide 6 in $81 \%$ overall yield Acid-mediated removal of THP followed by azide formation using $\mathrm{NaN}_{3}$ afforded alkyl azide 7 in $94 \%$ overall yield.

Preparation of vinylogous amide 9 was then achieved by a twostep sequence: (a) LAH-mediated azide reduction to give a primary amine with concomitant reduction of the alkyne revealing the olefin functionality; and (b) dehydrative condensation of this primary amine with 1,3-cyclohexanedione. Oxidation of the secondary allylic alcohol in 9 with $\mathrm{MnO}_{2}$ at ambient temperature provided enone $\mathbf{1 0}$ in $85 \%$ yield. We were poised to investigate the viability of the enone aza- $[3+3]$ annulation.

Our initial efforts to employ enone substrate $\mathbf{1 0}$ met with failure when using up to $500 \mathrm{~mol} \%$ of piperidinium chloride [65] (Table 1 , entry 1 ) or $100 \mathrm{~mol} \%$ piperidinium acetate salts (Table 1 , entry 2); even at higher temperatures of $120^{\circ} \mathrm{C}$, these chloride and acetate salts proved to be ineffective (Table 1, entry 3 ). We then explored salts prepared from stronger acids such as $(+)-$ camphorsulfonic acid (CSA) and trifluoroacetic acid, which should tend to dissociate easier in the reaction medium and lead to a more reactive vinyl iminium salt intermediate $\mathbf{1 b}$. We were

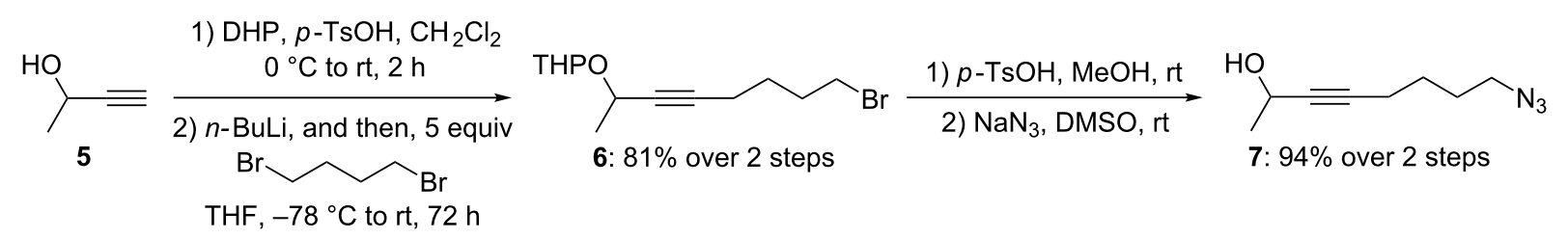
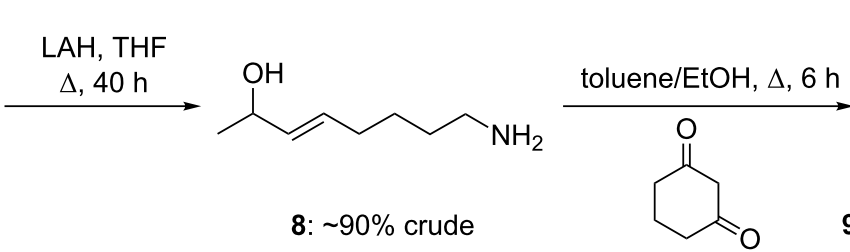<smiles>CC(O)C/C=C\CCNC1=CC(=O)CCC1</smiles>

$\mathrm{MnO}_{2}$, acetone, $\mathrm{rt}, 5 \mathrm{~h}$

9: $51 \%$ overall from 7<smiles>CCC(=O)/C=C/CCCCNC1=CC(=O)CCC1</smiles>

10: $85 \%$ 
Table 1: Catalyst screening and optimization

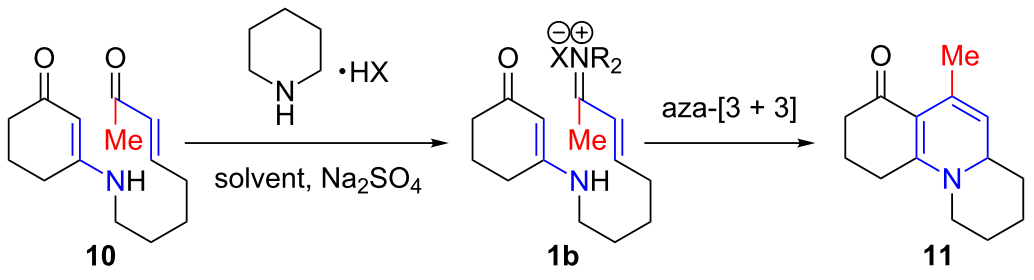

\begin{tabular}{|c|c|c|c|c|c|c|}
\hline entry $^{a}$ & $\mathrm{HX}(\mathrm{mol} \%)$ & solvent & temp $\left({ }^{\circ} \mathrm{C}\right)$ & time $(\mathrm{h})$ & conv. $(\%)$ & yield $(\%)^{b}$ \\
\hline 1 & $\mathrm{HCl}(500)$ & EtOAc/toluene & 100 & 16 & 0 & - \\
\hline 2 & HOAc (100) & EtOAc & 85 & 12 & 0 & - \\
\hline 3 & HOAc (500) & toluene & 120 & 16 & 0 & - \\
\hline 4 & $(+)-\operatorname{CSA}^{\mathrm{C}}(100)$ & toluene & 120 & 12 & 100 & 60 \\
\hline 5 & $\mathrm{HO}_{2} \mathrm{CCF}_{3}(500)$ & toluene & 85 & 7 & 79 & 39 \\
\hline 6 & $\mathrm{HO}_{2} \mathrm{CCF}_{3}(100)$ & toluene & 85 & 5 & 100 & 50 \\
\hline 7 & $\mathrm{HO}_{2} \mathrm{CCF}_{3}(100)$ & EtOAc/toluene & 110 & 4 & 92 & 41 \\
\hline 8 & $\mathrm{HO}_{2} \mathrm{CCF}_{3}(50)$ & toluene & 150 & 3 & 100 & 87 \\
\hline 9 & $\mathrm{HO}_{2} \mathrm{CCF}_{3}(90)$ & toluene & $\mathrm{MW}^{\mathrm{d}}$ & 1.5 & 94 & 65 \\
\hline
\end{tabular}

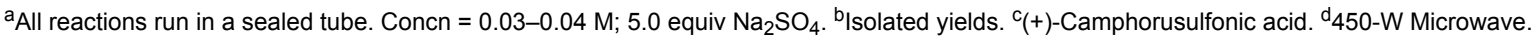

elated to observe that the use of $100 \mathrm{~mol} \%$ of piperidinium CSA salt in toluene at $120{ }^{\circ} \mathrm{C}$ provided $100 \%$ conversion with $60 \%$ yield of cycloadduct 11 (Table 1, entry 4). Further optimizations using trifluoroacetate salt (Table 1, entries 5-8) revealed that the yield could be improved to $87 \%$, while lowering the catalyst loading from $500 \mathrm{~mol} \%$ to $50 \mathrm{~mol} \%$, although the reaction temperature was raised to $150{ }^{\circ} \mathrm{C}$. Lastly, we also examined the use of microwave irradiation $[66,67]$ and observed a distinct rate enhancement (Table 1, entry 9).

The observed reactivity difference of the trifluoroacetate and camphorsulfonic acid salts, as compared to the chloride and acetate salts, can be attributed to the rate at which they promote vinyl iminium ion formation through a "balanced act" [12]. The difference in reactivity is related to the dissociation capacity of the respective amine salts. Since both "free amine" and "free acid" are needed in a synergistic manner to generate the vinyl iminium ion from the corresponding enone, the ability of the amine salt to dissociate to its "free amine" and "free acid" can exert an impact on the rate of the iminium formation. The low reactivity of the chloride salt can be attributed to its higher resistance toward dissociation, or is simply a tighter ion-pair compared to the CSA and the trifluoroacetate salt. At the same time, the formation of vinyl iminium ion from carbonyl systems and the "free amine" is also promoted by protonation of the carbonyl group via the "free acid". Consequently, the increased reactivity of the CSA and trifluoroacetate salt from the acetate salt can be attributed to a higher acidity of the acids.
After establishing the feasibility of the enone version of the intramolecular aza-[3 + 3] annulation we turned our attention to propyleine (12) (see Figure 2 and Scheme 3) as a possible target to showcase the new enone aza-[3 +3$]$ annulation. Propyleine (12) was isolated in 1972 from Propylaea quatuordecimpunctata in a continued effort by Tursch and co-workers [46,47] in their isolation of the azaphenalene family of defensive alkaloids from various ladybug beetles [38-45]. Mueller and Thompson [48] in 1980 found it interesting that the isomeric enamine named isopropyleine (14) was not reported in the original paper $[46,47]$ taking into account that the isolation conditions involved acid-base extractions. It is conceivable that propyleine (12) and isopropyleine (14) could be interconvertable under acidic conditions via intermediate iminium salt 13.

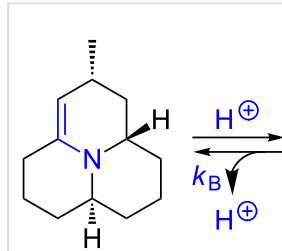

12: propyleine

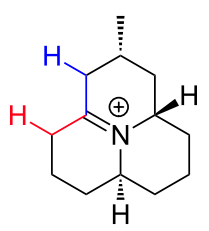

13

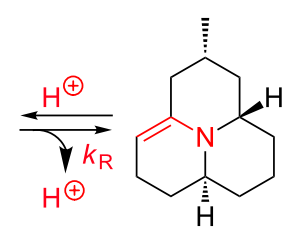

14: isopropyleine
Scheme 3: Propyleine-isopropeleine interconversion.

To investigate this matter, Mueller and Thompson carried out the first and the only synthesis of propyleine known to date 


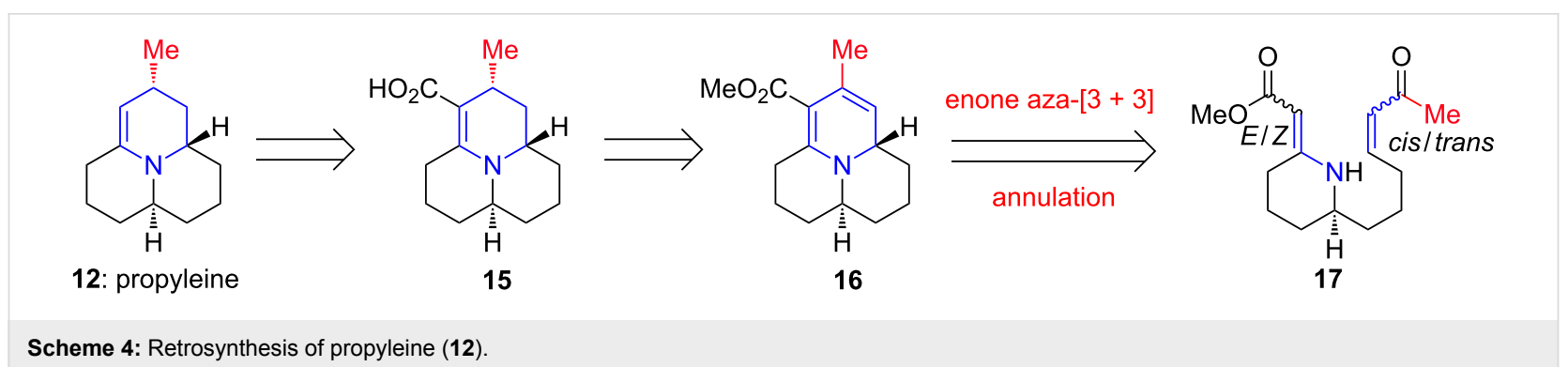

Scheme 4: Retrosynthesis of propyleine (12).

[48]. They were able to take a mixture of propyleine and isopropyleine with 1:3 ratio as determined by ${ }^{1} \mathrm{H}$ NMR and watch two sets of proton resonances collapse into one that corresponds to the iminium salt $\mathbf{1 3}$ after addition of TFA. This experiment strongly suggested that propyleine (12) and isopropyleine (14) could equilibrate under acidic conditions, thereby implying that the observed ratio of $\mathbf{1 2}$ and $\mathbf{1 4}$ represents a thermodynamic one in favor of the more stable isopropyleine [48]. With these experimental findings, Mueller and Thompson concluded that the alkaloid isolated by Tursch and co-workers $[46,47]$ was in fact a mixture of readily interconvertable 12 and 14.

We found this controversy in the isolation and total synthesis papers an interesting one that deserves further investigations. Consequently, we performed ab initio calculations on $\mathbf{1 2}$ and $\mathbf{1 4}$ to gain insight into their relative thermodynamic stability. Models of the most stable conformers and their corresponding energies are shown in Figure 3. To our surprise, propyleine (12) is $2.59 \mathrm{kcal} \mathrm{mol}^{-1}$ more stable than isopropyleine (14), which is the opposite of the Mueller-Thompson postulation [48]. Our calculations suggest that the ratio obtained from the Mueller-Thompson study was likely determined by the kinetics ( $k_{\mathrm{B}}$ versus $k_{\mathrm{R}}$ ) in the deprotonation step or the tautormerization process from the iminium salt $\mathbf{1 3}$, and not by thermodynamics as originally proposed. Resolving this interesting literature controversy added extra incentive for us to pursue propyleine.

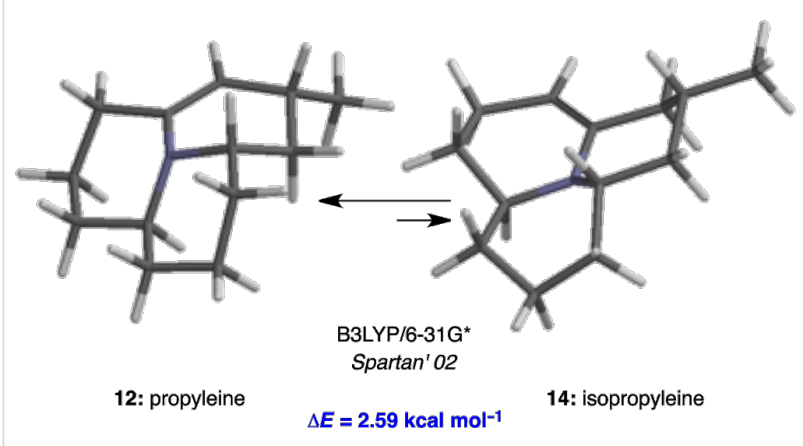

Figure 3: Relative stabilities of propyleine and isopropyleine.
Retrosynthetically, we envisioned propyleine (12) to come from the decarboxylation reaction of vinylogous carbamic acid $\mathbf{1 5}$ $[10,28]$, which could be derived from stereoselective hydrogenation of the endocyclic olefin in tricycle 16 (Scheme 4). Vinylogous urethane $\mathbf{1 6}$ should be accessible via our intramolecular aza- $[3+3]$ annulation of enone 17 . Enone 17 could be $E$ or $Z$ with respect to the vinylogous urethane olefin, and cis or trans with respect to the enone double bond. Thus, from the spectroscopic analysis stand point, synthesis of $\mathbf{1 7}$ could be messy.

In the forward direction to synthesize 17, we used the approach developed in our model study for the synthesis of precoccinelline, hippodamine and myrrhine alkaloids [30,31]. Specifically, TBDPS-protected 3-butyne-2-ol 18 was converted to bromoalkene 19 in two steps involving alkylation with an excess of dibromopropane and subsequent Lindlar's hydrogenation (Scheme 5). Grignard addition to the glutarimide $\mathrm{Mg}$-salt $\mathbf{2 0}$ followed by reduction of the Mg salt $\mathbf{2 1}$ afforded lactam $\mathbf{2 2}$ as an inseparable 1:1 mixture of two diastereomers in $77 \%$ overall yield [68-70].

Vinylogous amide $\mathbf{2 3}$ was prepared by $O$-methylation of lactam 22 with freshly distilled MeOTf followed by condensation with Meldrum's acid in the presence of $\mathrm{Ni}(\mathrm{acac})_{2}$. Treatment of $\mathbf{2 3}$ with $\mathrm{MeONa}$ in $\mathrm{MeOH}$ under reflux gave vinylogous urethane 24. It is noteworthy that the geometry of the vinylogous urethane double bond exclusively favored $Z$, presumably due to the internal hydrogen bonding. Cleavage of the TBDPS group with TBAF provided allylic alcohol 25 in 79\% from 23. However, submission of $\mathbf{2 5}$ to the standard $\mathrm{MnO}_{2}$ oxidation procedure did not lead to enone 17 , with only the starting material being recovered (Table 2). After extensive screening of various oxidation protocols, we succeeded with the Doering-Parikh conditions [71], and the cis geometry of the enone olefin was preserved under these conditions.

With enone 17-cis in hand, we studied its intramolecular aza$[3+3]$ annulation reaction utilizing piperidinium salts (Table 3). When compound 17-cis was treated with the acetate salt in EtOAc at $\mathrm{rt}$, no reaction was observed after $18 \mathrm{~h}$ 
1) $n$-BuLi, THF, and then
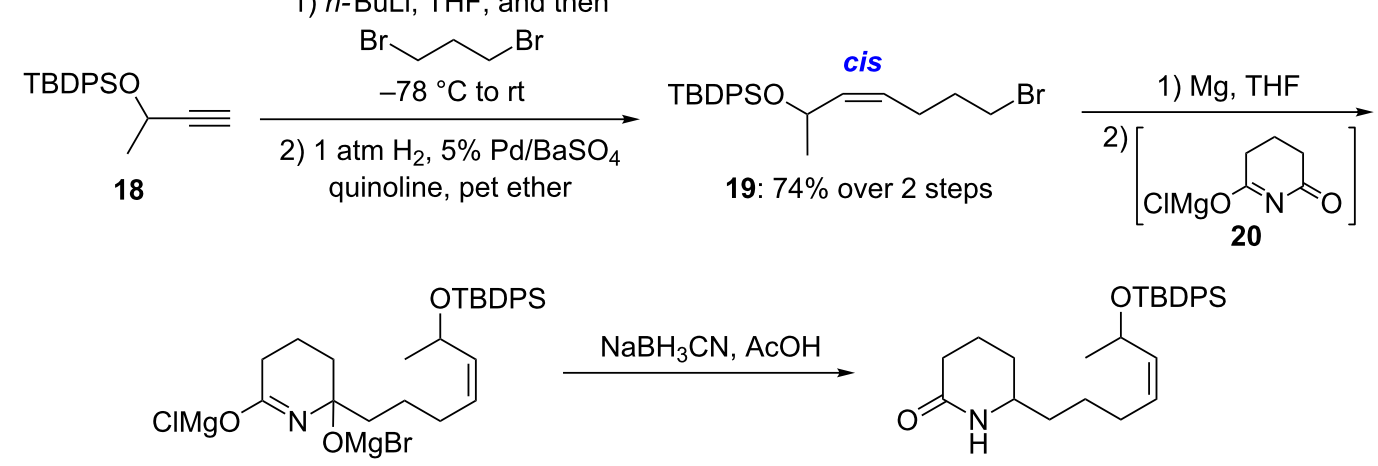

21

22: $77 \%$ overall
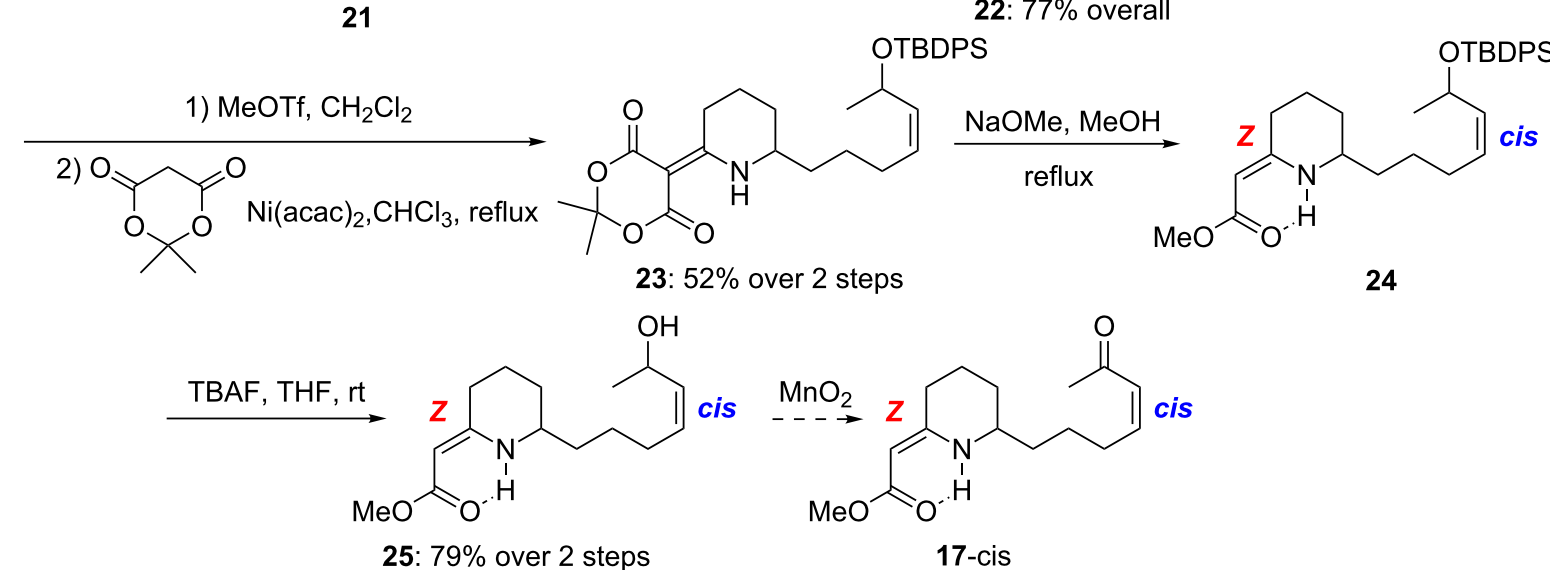

Scheme 5: Synthesis of allyl alcohol 25

Table 2: Synthesis of the annulation precursor 17.

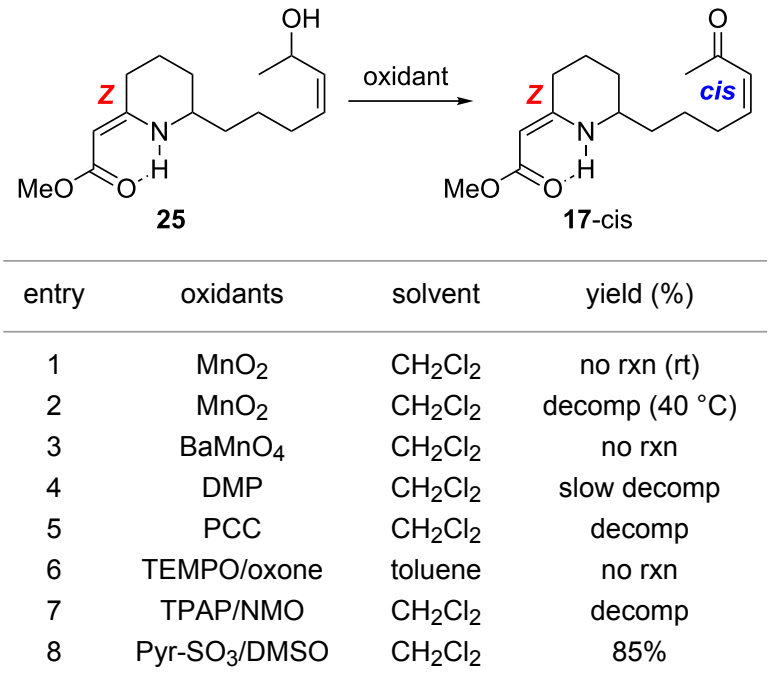

(Table 3, entry 1). Heating this reaction mixture at $85{ }^{\circ} \mathrm{C}$ for $12 \mathrm{~h}$ only led to slow isomerization of cis-enone $\mathbf{1 7}$ to the thermodynamically more stable trans-isomer again with no forma- tion of the desired annulation product 16 (Table 3, entry 2). The inefficiency of the piperidinium acetate salt in the intramolecular $a z a-[3+3]$ annulation of enones was consistent with our previous findings (see Table 1). We were also not successful in converting enone 17-cis to the desired tricycle 16 using the more reactive trifluoroacetate salt and EtOAc as the solvent. In this case also only isomerization to trans-enone was detected (Table 3, entry 3). Heating this reaction to $130{ }^{\circ} \mathrm{C}$ led to eventual decomposition of the starting material (Table 3 , entry 4 ).

However, when enone 17 -cis was heated in toluene at $100{ }^{\circ} \mathrm{C}$, complete consumption of starting material was observed after $5 \mathrm{~h}$ (Table 3, entry 5). Even though the reaction was relatively messy, the formation of the desired cycloadduct $\mathbf{1 6}$ was confirmed by the presence of characteristic signals in the ${ }^{1} \mathrm{H}$ NMR spectra of the crude mixture. Unfortunately, attempts to isolate the annulation product in pure form were not successful, probably due to the high instability of the electron-rich dihydropyridine moiety in 16. Based on our previous experience with precarious annulation products, in situ hydrogenation was then carried out, and we managed to track down $\sim 30 \%$ of the desired reduced aza-annulation product $\mathbf{2 6}$, although stereoselectivity for the reduction was modest. We ultimately elected 


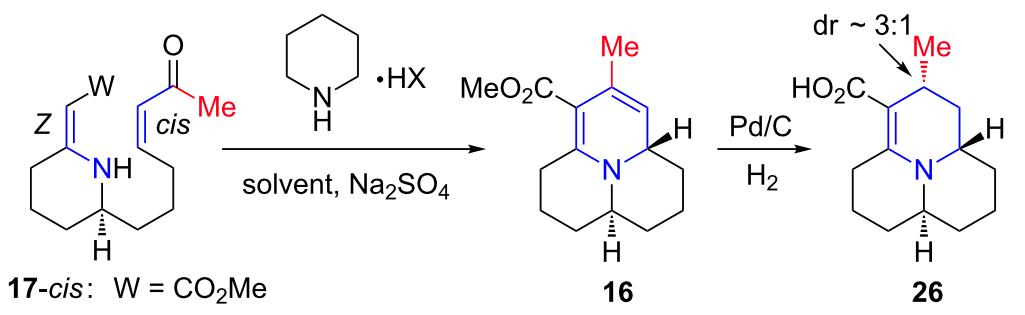

\begin{tabular}{|c|c|c|c|c|c|}
\hline entry $^{a}$ & $\mathrm{HX}(1.0$ equiv $)$ & solvent & temp $\left({ }^{\circ} \mathrm{C}\right)$ & time $(\mathrm{h})$ & yield $(\%)^{b}$ \\
\hline 1 & HOAC & EtOAc & 25 & 18 & - \\
\hline 2 & HOAc & EtOAc & 85 & 12 & 17-trans \\
\hline 3 & $\mathrm{HO}_{2} \mathrm{CCF}_{3}$ & EtOAc & 55 & 12 & 17-trans \\
\hline 4 & $\mathrm{HO}_{2} \mathrm{CCF}_{3}$ & EtOAc & 130 & 12 & decomp \\
\hline 5 & $\mathrm{HO}_{2} \mathrm{CCF}_{3}$ & toluene & 100 & 5 & $30 \%$ of $\mathbf{2 6}$ \\
\hline
\end{tabular}

aAll reactions run in a sealed tube. Concn $=0.03-0.04 \mathrm{M} ; 5.0$ equiv $\mathrm{Na}_{2} \mathrm{SO}_{4}$. b/solated yields.

not to force our way toward propyleine using the enone aza$[3+3]$ annulation, as we succeeded in total syntheses of other members of the azaphenalene alkaloid family through annulations with enals $[30,31]$. While it is disappointing that this particular system may have lacked sufficient stability for this to be a suitable synthetic approach, success in an enone version of intramolecular aza-[3 +3$]$ annulation will allow us to find future applications.

\section{Conclusion}

Herein, we have described a successful enone version of intramolecular aza-[3+3] annulation reaction. Use of piperidinium trifluoroacetate salt as the catalyst and toluene as the solvent appears to be critical for a successful annulation. We also demonstrated for the first time that microwave irradiation can accelerate aza- $[3+3]$ annulation reactions. An attempt to expand the scope of enone aza-[3+3] annulation was made in the form of propyleine synthesis as a proof of concept. While the synthesis of an enone annulation precursor was successfully accomplished, the annulation itself proved to be challenging and was only modestly successful. Future investigations are underway to pursue alkaloid synthesis via enone aza-[3+3] annulation.

\section{Supporting Information}

\section{Supporting Information File 1}

Experimental section.

[http://www.beilstein-journals.org/bjoc/content/ supplementary/1860-5397-9-131-S1.pdf]

\section{Acknowledgements}

Authors thank NIH [NS38049] for financial support.

\section{References}

1. Harrity, J. P. A.; Provoost, O. Org. Biomol. Chem. 2005, 3, 1349. doi:10.1039/b502349c

See for a leading review on hetero-[3+3] annulations.

2. Hsung, R. P.; Kurdyumov, A. V.; Sydorenko, N. Eur. J. Org. Chem. 2005, 23. doi:10.1002/ejoc.200400567

See for a leading review on hetero-[3 +3] annulations.

3. Buchanan, G. S.; Feltenberger, J. B.; Hsung, R. P. Curr. Org. Synth. 2010, 7, 363. doi:10.2174/157017910791414490 See for a leading review on aza-[3+3] annulations.

4. Lawrence, A. K.; Gademann, K. Synthesis 2008, 331. doi:10.1055/s-2008-1032134

See for a leading review on aza-[3+3] annulations.

5. Sklenicka, H. M.; Shen, H. C.; Wei, L.-L.; Zehnder, L. R.; McLaughlin, M. J.; Hsung, R. P. Trends Heterocycl. Chem. 2001, 7, 1-24.

6. Hsung, R. P.; Cole, K. P. The Total Synthesis of (-)-Arisugacin A. In Strategies and Tactics in Organic Synthesis; Harmata, M., Ed.; Pergamon Press: Oxford, 2004; Vol. 4, pp 41-70.

7. Tang, Y.; Oppenheimer, J.; Song, Z.; You, L.; Zhang, X.; Hsung, R. P. Tetrahedron 2006, 62, 10785. doi:10.1016/j.tet.2006.08.054

8. Hsung, R. P.; Wei, L.-L.; Sklenicka, H. M.; Douglas, C. J.; McLaughlin, M. J.; Mulder, J. A.; Yao, L. J. Org. Lett. 1999, 1, 509. doi:10.1021/ol990107v

See for method development.

9. Sklenicka, H. M.; Hsung, R. P.; Wei, L.-L.; McLaughlin, M. J.; Gerasyuto, A. I.; Degen, S. J. Org. Lett. 2000, 2, 1161. doi:10.1021/ol000049+

10. McLaughlin, M. J.; Hsung, R. P.; Cole, K. C.; Hahn, J. M.; Wang, J. Org. Lett. 2002, 4, 2017. doi:10.1021/ol020052o

11. Sydorenko, N.; Hsung, R. P.; Darwish, O. S.; Hahn, J. M.; Liu, J. J. Org. Chem. 2004, 69, 6732. doi:10.1021/jo049108d 
12. Gerasyuto, A. I.; Hsung, R. P.; Sydorenko, N.; Slafer, B. W. J. Org. Chem. 2005, 70, 4248. doi:10.1021/jo050171s

13. Sydorenko, N.; Hsung, R. P.; Vera, E. L. Org. Lett. 2006, 8, 2611. doi:10.1021/ol060932t

14. Ghosh, S. K.; Buchanan, G. S.; Long, Q. A.; Wei, Y.; Al-Rashid, Z. F.; Sklenicka, H. M.; Hsung, R. P. Tetrahedron 2008, 63, 883. doi:10.1016/j.tet.2007.09.089

15. Buchanan, G. S.; Dai, H.; Hsung, R. P.; Gerasyuto, A. I.; Schienebeck, C. M. Org. Lett. 2011, 13, 4402. doi:10.1021/ol2017438

16. Wei, L.-L.; Hsung, R. P.; Sklenicka, H. M.; Gerasyuto, A. I. Angew. Chem., Int. Ed. 2001, 40, 1516. doi:10.1002/1521-3773(20010417)40:8<1516::AID-ANIE1516>3.0.CO; $2-\mathrm{V}$

See for investigations related to intramolecular annulations.

17. Sklenicka, H. M.; Hsung, R. P.; McLaughlin, M. J.; Wei, L.-L.; Gerasyuto, A. I.; Brennessel, W. W. J. Am. Chem. Soc. 2002, 124, 10435. doi:10.1021/ja020698b

18. laroshenko, V. O.; Ali, S.; Babar, T. M.; Dudkin, S.; Mkrtchyan, S.; Rama, N. H.; Villinge, A.; Langer, P. Tetrahedron Lett. 2011, 52, 373. doi:10.1016/j.tetlet.2010.11.028 See for recent studies in aza-annulations.

19. Guo, H.; Xu, Q.; Kwon, O. J. Am. Chem. Soc. 2009, 131, 6318 doi:10.1021/ja8097349

20. Jeanne Alladoum, J.; Toum, V.; Hebbe, S.; Kadouri-Puchot, C.; Dechoux, L. Tetrahedron Lett. 2009, 50, 617. doi:10.1016/j.tetlet.2008.11.070

21. Zhong, W.; Lin, F.; Chen, R.; Su, W. Synthesis 2008, 2561. doi:10.1055/s-2008-1078601

22. Hayashi, Y.; Gotoh, H.; Masui, R.; Ishikawa, H. Angew. Chem., Int. Ed 2008, 47, 4012. doi:10.1002/anie.200800662

23. Mancey, N. C.; Butlin, R. J.; Harrity, J. P. A. Synlett 2008, 2647. doi:10.1055/s-0028-1083525

24. Trost, B. M.; Dong, G. Org. Lett. 2007, 9, 2357. doi:10.1021/ol070742y

25. Provoost, O. Y.; Hazelwood, A. J.; Harrity, J. P. A. Beilstein J. Org. Chem. 2007, 3, No. 8. doi:10.1186/1860-5397-3-8

26. Luo, S.; Zificsak, C. A.; Hsung, R. P. Org. Lett. 2003, 5, 4709. doi:10.1021/ol030114q See for natural product synthesis using the intramolecular annulation

27. Sydorenko, N.; Zificsak, C. A.; Gerasyuto, A. I.; Hsung, R. P. Org. Biomol. Chem. 2005, 3, 2140. doi:10.1039/b503862f

28. Swidorski, J. J.; Wang, J.; Hsung, R. P. Org. Lett. 2006, 8, 777. doi:10.1021/ol053059p

29. Wang, J.; Swidorski, J. J.; Sydorenko, N.; Hsung, R. P.; Coverdale, H. A.; Kuyava, J. M.; Liu, J. Heterocycles 2006, 70, 423. doi:10.3987/COM-06-S(W)40

30. Gerasyuto, A. I.; Hsung, R. P. Org. Lett. 2006, 8, 4899. doi:10.1021/ol0619359

31. Gerasyuto, A. I.; Hsung, R. P. J. Org. Chem. 2007, 72, 2476. doi:10.1021/jo062533h

32. Zhang, Y.; Gerasyuto, A. I.; Long, Q. A.; Hsung, R. P. Synlett 2009, 237. doi:10.1055/s-0028-1087661

33. Robinson, R. J. Chem. Soc. 1917, 762.

34. Boger, D. L.; Patel, M. Progress in Heterocyclic Chemistry; Suschitzky. H.; Scriven, E. F. V., Eds.; Pergamon: London, 1989, Vol. 1, pp. 30 ff. See for a leading review.

35. Boger, D. L. Chem. Rev. 1986, 86, 781. doi:10.1021/cr00075a004

36. Boger, D. L. Tetrahedron 1983, 39, 2869.

doi:10.1016/S0040-4020(01)92154-4
37. Comprehensive Organic Synthesis; Trost, B. M.; Fleming, I., Eds.; Pergamon Press, 1991; Vol. 4 and 5.

See chapters on cycloaddition reactions.

38. Happ, G. M.; Eisner, T. Science 1961, 134, 329 doi:10.1126/science.134.3475.329 See for leading reviews on azaphenalene alkaloids.

39. King, A. G.; Meinwald, J. Chem. Rev. 1996, 96, 1105. doi:10.1021/cr950242v

40. Stevens, R. V. Acc. Chem. Res. 1984, 17, 289. doi:10.1021/ar00104a005

41. Tursch, B.; Daloze, D.; Dupont, M.; Pasteels, J. M.; Tricot, M.-C. Experientia 1971, 27, 1380. doi:10.1007/BF02154239 See for isolations of azaphenalene alkaloids.

42. Karlsson, R.; Losman, D. J. Chem. Soc., Chem. Commun. 1972, 626. doi:10.1039/C39720000626

43. Tursch, B.; Daloze, D.; Pasteels, J. M.; Cravador, A.; Braekman, J. C.; Hootele, C.; Zimmermann, D. Bull. Soc. Chim. Belg. 1972, 81, 649.

44. Tursch, B.; Daloze, D.; Braekman, J. C.; Hootele, C.; Cravador, A.; Losman, D.; Karlsson, R. Tetrahedron Lett. 1974, 409. doi:10.1016/S0040-4039(01)82228-0

45. Tursch, B.; Daloze, D.; Braekman, J. C.; Hootele, C.; Pasteels, J. M. Tetrahedron 1975, 31, 1541. doi:10.1016/0040-4020(75)87008-6

46. Tursch, B.; Daloze, D.; Hootele, C. Chimia 1972, 26, 74. See for isolation of propyleine.

47. Moore, B. P.; Brown, W. V. Insect Biochem. 1978, 8, 393. doi:10.1016/0020-1790(78)90027-6

48. Mueller, R. H.; Thompson, M. E. Tetrahedron Lett. 1980, 21, 1097. doi:10.1016/S0040-4039(01)83923-X See for a total synthesis of propyleine.

49. Ma, X.; Gang, D. R. Nat. Prod. Rep. 2004, 21, 752. doi:10.1039/b409720n See for leading reviews on lycopodium alkaloids.

50. Ayer, W. A. Nat. Prod. Rep. 1991, 8, 455. doi:10.1039/np9910800455

51. MacLean, D. B. In The Alkaloids; Brossi, A., Ed.; Academic Press: New York, 1985; Vol. 26, p 241.

52. Henry, T. A. The Plant Alkaloids, 4th ed.; The Blackiston Company, 1949; pp $394 \mathrm{ff}$

53. Shamma, M. In The Isoquinoline Alkaloids. Chemistry and Pharmacology; Blomquist, A. T.; Wasserman, H., Eds.; Organic Chemistry, Vol. 25; Academic Press: New York, 1972; pp 427-455.

54. Brown, R. T. In The Chemistry and Biology of Isoquinoline Alkaloids; Phillipson, J. D.; Roberts, M. F.; Zenk, M. H., Eds.; Springer-Verlag: Berlin, 1985; pp 205-207.

55. Szántay, C. In The Alkaloids. Chemistry and Biology; Cordell, G. A., Ed.; Academic Press: London, 1998; Vol. 50, pp 379-380.

56. Rapoport, H.; Windgassen, R. J.; Hughes, N. A.; Onak, T. P. J. Am. Chem. Soc. 1960, 82, 4404. doi:10.1021/ja01501a069

57. Janot, M.-M. Tetrahedron 1961, 14, 113. doi:10.1016/0040-4020(61)80089-6

58. Wiegrebe, W.; Kramer, W. J.; Shamma, M. J. Nat. Prod. 1984, 47, 397. doi:10.1021/np50033a001

59. Piso, W.; Marcgraf, G. Historia Naturalis Brasiliae, Elzevir, L. Ed.; Amsterdam, 1648; Ch. 65, De Ipecacuanha, eiusque facultatibus, pp 101-102.

60. Wild, R. B. The Pharmacology of ipecacuanha Alkaloids. In The Western Druggist; G. P. Engelhardt and Co.: Chicago, 1897; Vol. 18, p 12.

61. Lloyd, U. J. Cephaelis ipecacuanha. In The Western Druggist, Chicago, August, 1897; Vol. 19, pp 346-350. 
62. The Merck Index: An Encyclopedia of Chemicals, Drugs, and Biologicals, 12th ed.; Budavari, S.; O'Neil, M. J.; Smith, A.; Heckelman, P. E.; Kinneary, J. F., Eds.; Merck and Co. Inc.: Whitehouse Station, NJ, 1996; pp 3600-3601.

63. Zimmerman, J. L.; Rudis, M. Chapter 73. In Critical Care Medicine. Principles of Diagnosis and Management in the Adult, 2nd ed.; Parrillo, J. E., Ed.; Mosby, Inc.: St. Louis, MO, 2002; pp 1506-1507.

64. Ma, W.-W.; Anderson, J. E.; McKenzie, A. T.; Byrn, S. R.; McLaughlin, J. L.; Hudson, M. S. J. Nat. Prod. 1990, 53, 1009. doi:10.1021/np50070a041

65. A mixture of EtOAc and toluene was employed to allow for both complete dissolution of the substrate and heating at higher temperatures.

66. Bose, D. S.; Kumar, R. K. Heterocycles 2006, 68, 549. doi:10.3987/COM-06-10668

See for an account on the use of microwaves in aza-[3 + 3] annulations.

67. Kang, Y.; Mei, Y.; Du, Y.; Jin, Z. Org. Lett. 2003, 5, 4481. doi:10.1021/ol030109m See for an account on the use of microwaves in oxa-[3 +3$]$ annulations.

68. Karstens, W. F. J.; Stol, M.; Rutjes, F. P. J. T.; Kooijman, H.; Spek, A. L.; Hiemstra, H. J. Organomet. Chem. 2001, 624, 244. doi:10.1016/S0022-328X(00)00935-9

69. Esch, P. M.; Hiemstra, H.; Klaver, W. J.; Speckamp, W. N. Heterocycles 1987, 26, 75. doi:10.3987/R-1987-01-0075

70. Evans, D. A.; Thomas, E. W.; Cherpeck, R. E. J. Am. Chem. Soc. 1982, 104, 3695. doi:10.1021/ja00377a026

71. Parikh, J. R.; Doering, W. v. E. J. Am. Chem. Soc. 1967, 89, 5505. doi:10.1021/ja00997a067

\section{License and Terms}

This is an Open Access article under the terms of the Creative Commons Attribution License (http://creativecommons.org/licenses/by/2.0), which permits unrestricted use, distribution, and reproduction in any medium, provided the original work is properly cited.

The license is subject to the Beilstein Journal of Organic Chemistry terms and conditions:

(http://www.beilstein-journals.org/bjoc)

The definitive version of this article is the electronic one which can be found at: doi:10.3762/bjoc. 9.131 